\title{
Rapid Time Response: A solution for Manufacturing Issue
}

\author{
N.Norazlin ${ }^{1}$, A.Y. Bani Hashim ${ }^{1}$, M.H.F.M.Fauadi ${ }^{1}$, Teruaki Ito ${ }^{2}$ and Zinvi Fu ${ }^{1}$ \\ ${ }^{1}$ Faculty of Manufacturing Engineering, Universiti Teknikal Malaysia Melaka,Hang Tuah Jaya, 76100 Durian Tunggal, Melaka, Malaysia \\ ${ }^{2}$ Institute of Technology and Science Tokushima University, Minami-Josanjima 2-1,Tokushima-shi, Tokushima, 77-8506 Japan.
}

\begin{abstract}
Respond time in manufacturing give the major impact that able to contribute too many manufacturing issues. Based on two worst case scenario occurred where Toyota in 2009 made a massive vehicles call due to car complexity of 11 major models and over 9 million vehicles. The recalls cost at least $\$ 2$ billion in cost of repair, lost deals and result in lost 5\% of its market share in United State of America, while A380 was reported on missing target in new production and leads to delayed market entry due to their weak product life cycle management (PLM). These cases give a sign to all industries to possess and optimize the facilities for better traceability in shortest time period. In Industry 4.0 , the traceability and time respond become the factors for high performance manufacturing and rapid time respond able to expedite the traceability process and strengthen the communication level between man, machine and management. The round trip time (RTT) experiment gives variant time respond between two difference operating system for intra and inter-platform signal. If this rapid time respond is adopted in any manufacturing process, the delay in traceability on every issue that lead to losses can be successfully avoided.
\end{abstract}

\section{Manufacturing Issues}

Based on two worst case scenario occurred in 2009 where Toyota made a massive vehicles call due to car complexity of 11 major models and over 9 million vehicles. The recalls cost at least $\$ 2$ billion in cost of repair and lost deals. The recall result in lost 5\% of its market share in United State of America and further drops foreseen [1]. While A380 was reported on missing target in new production and leads to delayed market entry due to their weak product life cycle management (PLM) [2]. These two cases give a sign to all industries to possess and optimize the facilities for better traceability in shortest time period.

The manufacturing issues are summarized in Figure 1 where it's divided into three main factors which are man, machine and management. To handle the complexity in manufacturing network, the future focused leadership and mind set is required. Furthermore the more intelligent equipment or machines occupied, the higher skill worker required to operate that. The challenge and manufacturing issues in Industry 4.0 is divided into three main factors which are man, machine and management. To handle the complexity in manufacturing network, the future focused leadership and mind set is required. Furthermore the more intelligent equipment or machines occupied, the higher skill worker required to operate that. Traceability become a main focused in this study where the usage of IoT (Internet of Things) is manipulating to track the product information and material used during manufacturing process. The traceability makes the whole manufacturing processes become visible and easy to manage.

Emerging manufacturing concerned on how fast the processes and information taken in order to meet the customer demand. To achieve that, the industry should deploy the new and innovative medium to be competitive and ready to face the market changing in anytime. Traceability and real time respond are indicators for effective communication in order to avoid any breakdown and ensure the raw material is continuously supply into manufacturing process. The more efficient of traceability system and rapid real time respond able to bring the manufacturing process into high performance of manufacturing. In this study, real time respond is shared where the time measured in millisecond (ms) through JAVA programming.

\subsection{Issues in PLM}

PLM emphasized the combination of people, process and data to be successfully implemented. However the implementation of PLM also contributes to several losses based on real case scenarios occurred around the world when it's neglected several factors. Figure 2 shows the six issues that been identified from the current study and the factors affected in sustainable PLM. 


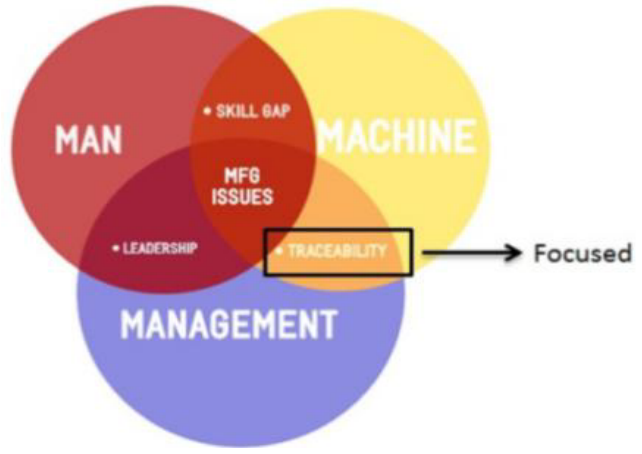

Figure 1. Current manufacturing issues faced. The challenge and manufacturing issues in Industry 4.0 is divided into three main factors which are man, machine and management. To handle the complexity in manufacturing network, the future focused leadership and mind set is required.

Green focused should provide an important competitive advantage instead of minimizing the environmental harm only. In to integrate environmental issues into new product development (NPD), the environmental factors must be considered in all stages of the manufacturing process [3]. The emerging of green technology involve two sides in manufacturing perspective, customers demand and supply from manufacturers which pressuring and responding to it. This point of view enforced the pre-production stage to consider the environmental issues in the design process [4]. The successful of green NPD involve a wide set of stakeholders and the suppliers plays a major role for NPD where it's begin from the design concept stage to the prototype development stage [3,5]. Collaboration and communication are two main factors for green NPD. Collaboration is defined as coordination and alignment with project teams since the green NPD having a broad demand and various inputs and multifunctional product development, to meet market and environmental regulatory requirements become a main reason why the team needs to be coordinated. Effective communication between stakeholders is needed in order to provide information to produce green NPD. The information become extremely valuable in preproduction stage where its involve design and testing in order to ensure the NPD is meet the environmental regulations.

Complexity in NPD required a stable system to manage the development process. To manage the entire PLM is not an easy activity in order to meet the target such as customer demand, early market entry, new invention product and etc. The transforming of virtual production (designing, testing and simulation) into physical production is difficult to control during phase of life. The managerial complexity of PLM becomes crossenterprise issues and even more challenging. Late market entry and exceed the targeted cost are the serious consequences faced if the company loses control in PLM [6]. It is proven by real cases reported when weak PLM was implemented.

Case 1: Toyota Company: Until year 2009, Toyota made a massive vehicles call due to car complexity of 11 major models and over 9 million vehicles. The recalls cost at least $\$ 2$ billion in cost of repair and lost deals. The recall result in lost 5\% of its market share in United State of America and further drops foreseen [1].

Case 2: Airbus Company: A380 reported on missing target in new production and leads to delayed market entry due to their weak product life cycle management (PLM) [2].

The fluctuation demand occurred when the awareness campaign on green product and keep the environment safe become effective. This point enforced company to create new product that comply with environment regulation. The interest in sustainable development growth rapidly when company start to consider mitigating the material used and waste product and any future weakness as well as inefficiencies can be avoided [7]. Organizing and managing the sustainable development and NPD become more complex and it's dependent on organized process and technology as a critical success factors $[8,9]$ PLM required technology as an integrative approach in order to manage the data and process for NPD towards sustainable and efficiently possible in new product process but not in development/design phase only [8].

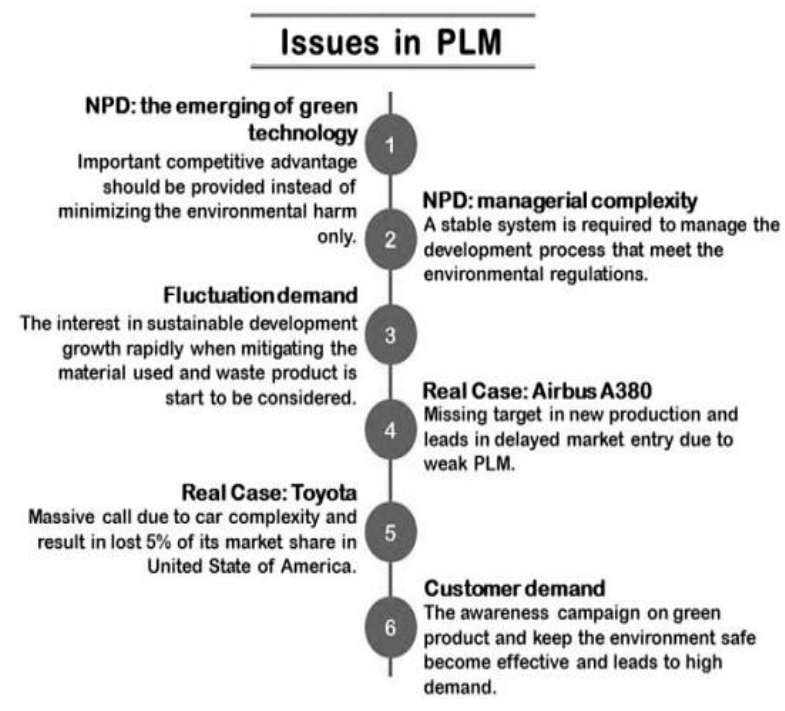

Figure 2. Issues in PLM. In PLM, there are three important factors that make it complete and works efficiently. People, process and data required good collaboration and by intervening the technology into PLM make it become more successful to merge the business globally.

Current practise of PLM is shows in Table 1 where the most application is neglected the technology invention in order to manage the data and process. The successful collaboration process can be achieved when PLM able to interact with coordination, information exchange, negotiation and solving conflicts [10]. In PLM, there are three important factors that make it complete and works efficiently. People, process and data required good collaboration and by intervening the technology into PLM make it become more successful to merge the business globally. To reduce the communication barrier cause by geographically factor and the used of web-based management or IoT seem the only way to make it successfully manage. Furthermore the manufacturing 
web-based only focus in early PLM stage which are preproduction and production only by neglecting the information trading between supplier, customer and retailer.

Gaps analysis as shown in Figure 3 has been concluded from the reviews on current PLM implementation and agent web-based application. Too focused on NPD is noticed as the first gap where current implementation or research put a lot of focused in preproduction stage in order to make sure the product development comply with the environment rules and regulations. Second gap reveal the poor information interaction and lack of data exploitation for the entire PLM and noticed that the sustainable NPD is only feasible to be done in pre-production only and hard to be implemented in the entire of PLM [8]. It is because the company lack of communication by ignoring the information exchange between supplier, customer and retailer become the third gap in current PLM practise. This point of view proved the idea proposed by [3] where the sustainable NPD should be involved with wide stakeholders. In order to achieve the sustainable PLM, the information exchange and trading is required in entire PLM. By emphasizing the IoT in PLM, it's able to make the idea of sustainable PLM happen with its ability to solve the complexity and expedite the process and secure communication network in management and production process.

Table 1. Studies reviewed on PLM. In PLM, there are three important factors that make it complete and works efficiently. People, process and data required good collaboration and by intervening the technology into PLM make it become more successful to merge the business globally.

\begin{tabular}{|c|c|c|c|}
\hline Author & Issues Focused & Industrial Focused & Idea Proposed \\
\hline [11] & $\begin{array}{lrrr}\text { Product Life } & \text { Cycle } & \text { Energy } \\
\text { Management } & \text { (PLEM): } & \text { Energy } \\
\text { consumption } & & \end{array}$ & $\begin{array}{l}\text { Manufacturing } \\
\text { Firms Area: design, } \\
\text { production and } \\
\text { serve process }\end{array}$ & IoT in PLEM \\
\hline [10] & $\begin{array}{l}\text { The interactions between SLM (Service } \\
\text { Life Cycle Management) and PLM } \\
\text { (Product Life Cycle Management) }\end{array}$ & $\begin{array}{l}\text { Manufacturing } \\
\text { Firms }\end{array}$ & $\begin{array}{l}\text { Combining the PLM with } \\
\text { SLM by using the IT } \\
\text { technology. }\end{array}$ \\
\hline [8] & New Product Development (NPD) & $\begin{array}{l}\text { Automotive } \\
\text { companies }\end{array}$ & Sustainability in NPD \\
\hline [12] & $\begin{array}{l}\text { Communication in Sustainable PLM } \\
\text { (Green Information System) }\end{array}$ & $\begin{array}{l}\text { Manufacturing } \\
\text { Firms }\end{array}$ & $\begin{array}{l}\text { Intelligent Product } \\
\text { Sustainal for } \\
\text { Applications }\end{array}$ \\
\hline [13] & Closed-loop PLM & $\begin{array}{l}\text { Production } \\
\text { Management }\end{array}$ & $\begin{array}{l}\text { Physical device i.e: sensor, } \\
\text { timer etc. is required to } \\
\text { achieve the level of intelligent } \\
\text { system/process }\end{array}$ \\
\hline [14] & $\begin{array}{l}\text { Non-effective application of lifecycle } \\
\text { management concepts }\end{array}$ & $\begin{array}{l}\text { Manufacturing and } \\
\text { Business }\end{array}$ & $\begin{array}{l}\text { Process oriented framework } \\
\text { to support effective PLM } \\
\text { implementation }\end{array}$ \\
\hline
\end{tabular}

\section{Industry 4.0}

Online customization and purchasing is a new disruptive purchasing model that affected the manufacturing system and chain. This model required an evolution management while the operational levels become a huge challenge [15]. Terms of Big Data cannot be denied in Industry 4.0 where the only effective solution to manage and control the complexity and disturbances is by adapting the manufacturing networks [16]. Behind the manufacturing networks, IoT, data exchange, product life cycle management (PLM), business web, social web, computer hardware and software become the pillars. It is view by [16] in Figure 4 that incorporates the recent trends in internet technologies that able to give better support to the Industry 4.0.

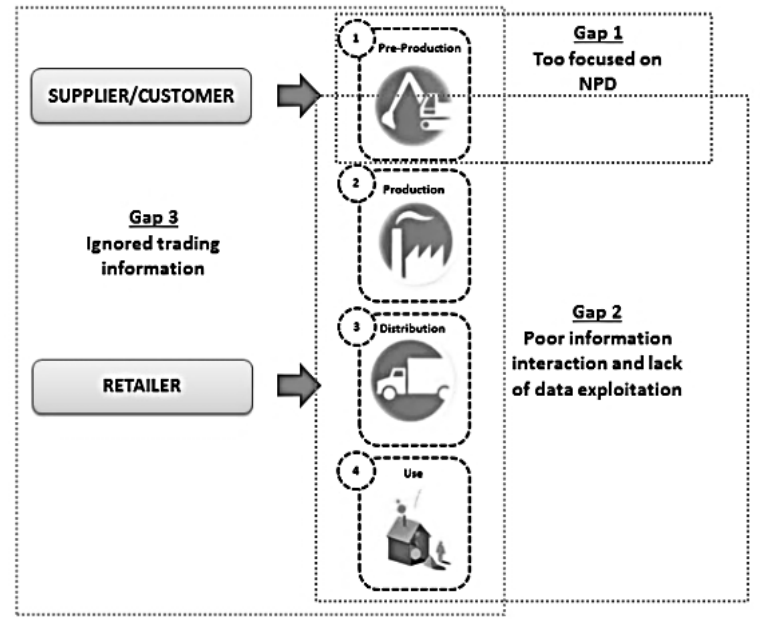

Figure 3. Gaps in current PLM practise. Current practise of PLM neglected the technology invention in order to manage the data and process. The successful collaboration process can be achieved when PLM able to interact with coordination, information exchange, negotiation and solving conflicts [10].

\section{Round Trip Time}

The purpose of the experiments in this section is to verify the optimal cost through round trip time (RTT). In manufacturing view, time plays the major in production and very significant with cost. Most of the manufacturing target emphasized the time period for every activities including communication. The RTT is measure by using socket communication between two or more computer.

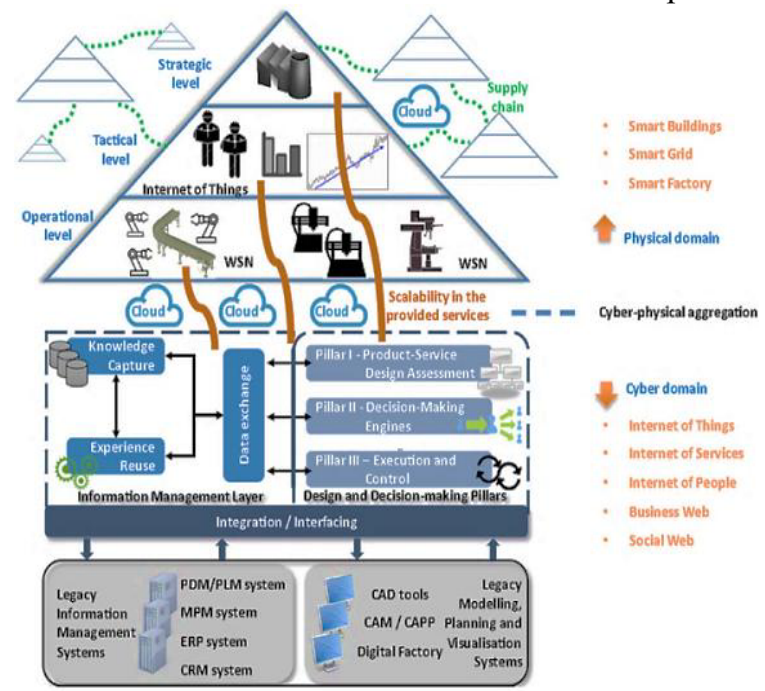

Figure 4. Manufacturing view in the future [16]. As an emerging manufacturing, the automation is not only automate the physical processes but data also include. [17] agreed that the automated of physical processes and information processing able to achieve a long term sustainable production. The automation processes become a 
goal in deterministic manufacturing and one of the criteria for Industry 4.0.

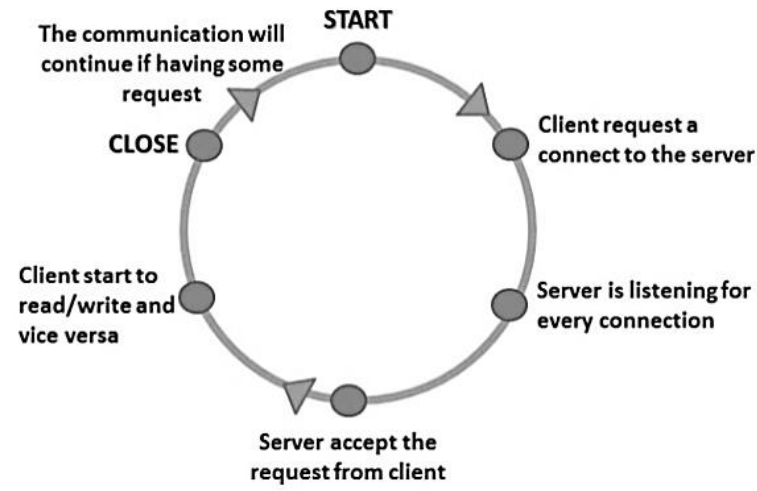

Figure 5. The general process cycle for one way communication through sockets and server. The activities are kept on happening until the server is disconnected.

There are two type of computer used which are local and remote computers that running over the network. The two-way communication between two programs running through socket that constitutes a client-server application. The connection process started with client send a request to the server on specific port. The server is on ready mode for listening and accepts the request from the client. Once the connection is accepted, the client able to use the socket to communicate with the server and the communication begin with read/write from their sockets. The process cycle is shown in Figure 5 below where the activities is keep on happening until the server is disconnected. The communication occurred in port 7999 on server network. The port can be changed and in this study, the port is randomly picked. Figure 6 show the general illustration for one way communication where the read and write is triggered by command "skt.getInputStream()" and "skt.getOutputStream()". While Figure 7 and Figure 8 shown the programming flow for Client and Server.
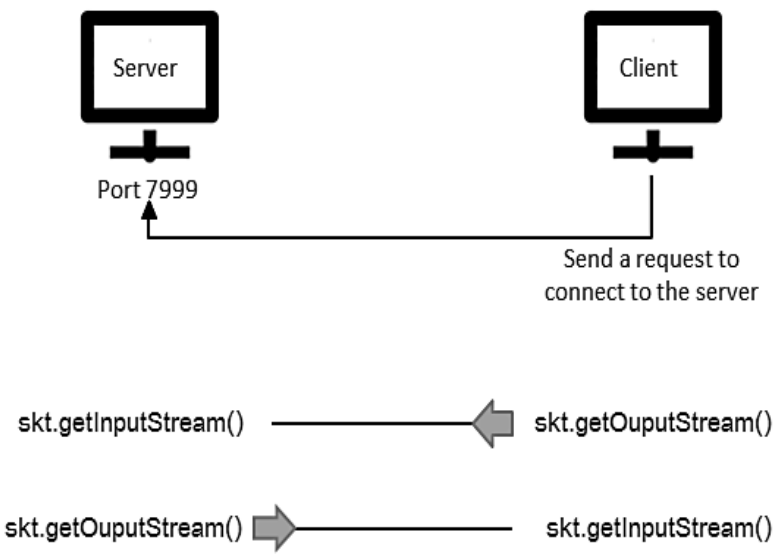

Figure 6. General illustration for one way communication on socket 7999. The communication occurred in port 7999 on server network. The port can be changed and the port can be picked randomly. Once the connection is accepted, the client able to use the socket to communicate with the server and the communication begin with read/write from their sockets.

\subsection{Machines Detail}

Most of the manufacturing target emphasized the time period for every activities including communication. The purpose of the experiments in this section is to verify the optimal cost through RTT. The RTT is measure by using socket communication between two or more computer involve client and server environment. The PC or workstation is referring to client which provides with friendly interface such as Windows. While a group of users is provide by server to client for sharing the server program [18].

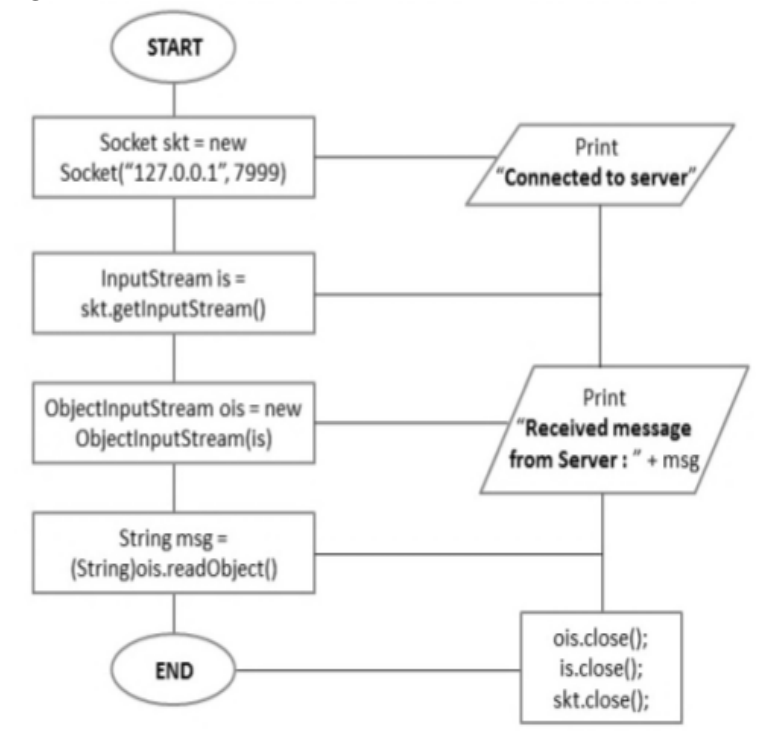

Figure 7. Programming flow for Client in RTT experiments. The communication where the read and write is triggered by command "skt.getInputStream()".

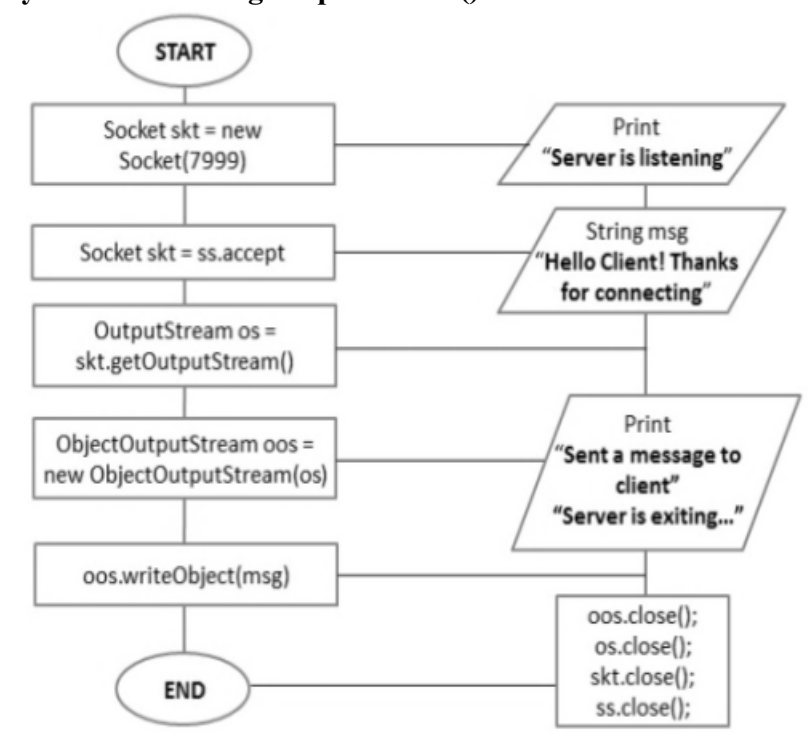

Figure 8. Programming flow for Server in RTT experiments. The communication where the read and write is triggered by command "skt.getOutputStream()".

There are two type of operating system used that running over the network where the details of machines (computers) used is shown in Table 2. The communication between two programs running through socket that constitutes a client-server application. The reason on choosing Windows operating system is because this Windows is widely used in industry and low minimum cost of investment. While Linux operating 
system is choose because of the level of security system and its performance for programming development and operation is better compared to Windows. The reasons why the industries do not want to adopt Linux into their environment because of complexity in term of usage and required a lot of training need to be provided for their employees.

Table 2. Machine details for RTT experiments. Windows and Linux as an operating system provide the communication link between users and the devices. The communication between two programs running through socket that constitutes a client-server application.

\begin{tabular}{cccc}
\hline $\begin{array}{c}\text { Machi } \\
\text { ne } \\
\text { name }\end{array}$ & $\begin{array}{c}\text { Operati } \\
\text { ng } \\
\text { System }\end{array}$ & RAM & $\begin{array}{c}\text { IP } \\
\text { Address }\end{array}$ \\
\hline V1 & Window & 4.00 & 120.17 .42 \\
& s 7 & GB & \\
V2 & Window & 4.00 & 120.17 .92 \\
& s 10 & GB & \\
V3 & Window & 4.00 & 120.17 .45 \\
& s 8 & GB & \\
V4 & Linux & 972.6 & 120.17 .19 \\
& Ubuntu & MB & 4 \\
\cline { 2 - 4 }
\end{tabular}

\section{Result and Discussion}

\subsection{Intra-Platform signal}

Intra-platform communication occurred as internal signal respond in one machine as shown in Figure 9. Huge difference of respond obtained by V3 compare to V1, V2 and V4. The different probably cause by the machine itself where V3 is frequently used for programming development compare to others. Furthermore the other machine is rarely used. However, the speed of network also contributes to the long period taken for every machine to respond.

\subsection{Inter-Platform Signal}

For the inter-platform signal responds involved difference server for every testing. Overall performance showed that the server V3 in Figure 12 gives the fastest signal respond in $14 \mathrm{~ms}$ compared to others. However, the V4 in Figure 13 shown the overall signal respond in $588 \mathrm{~ms}$ where the Linux is an operating system for that machine. Linux give a lot of benefit for computer and network development but it less to be used for manufacturing purpose. For server V1 in Figure 10 and server V2 in Figure 11 shown the instability occurred with overall signal respond is $644 \mathrm{~ms}$ and $645 \mathrm{~ms}$ respectively.

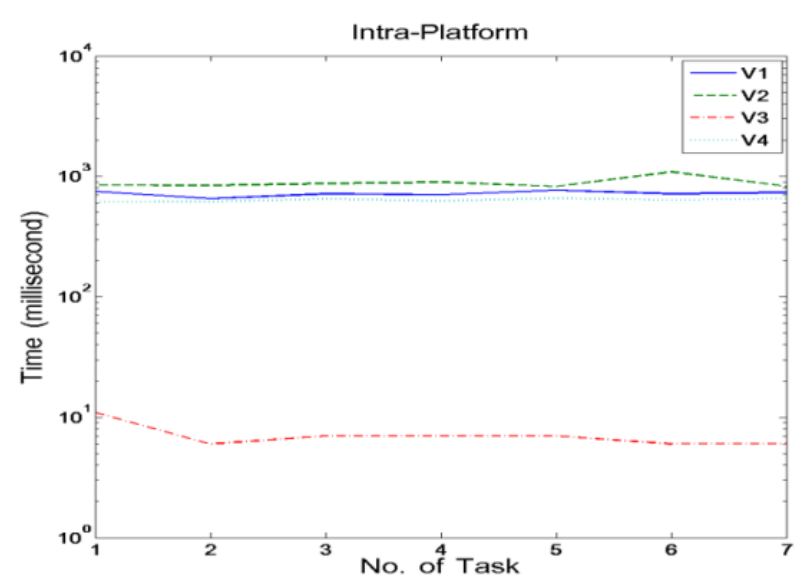

Figure 9. Intra-Platform signal respond in time (millisecond). Machine V3 obtained rapid respond compared to other machines. This frequency of used for programming may become a contribution factor.

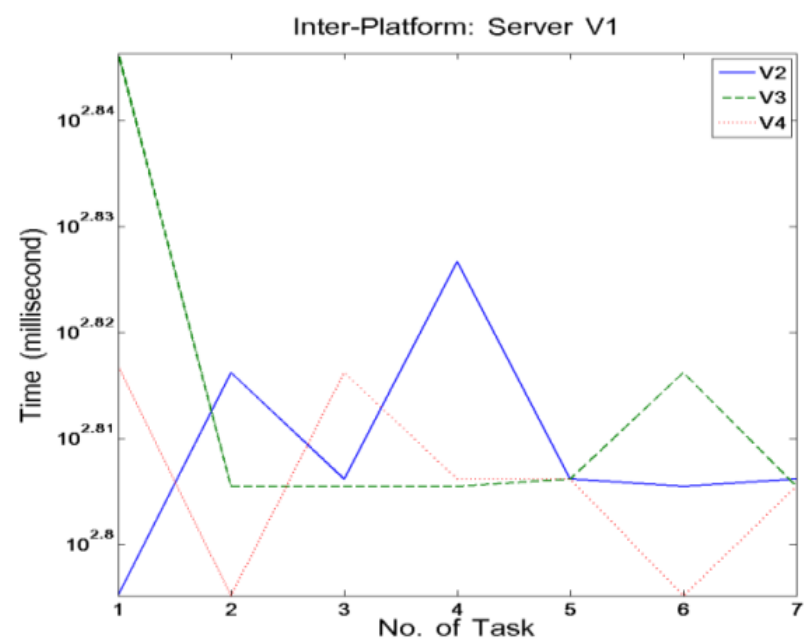

Figure 10. Inter-Platform signal respond in time (millisecond) for Server V1. Instability of connection show in server V1, however machine $V 3$ shows stability in one way communication.

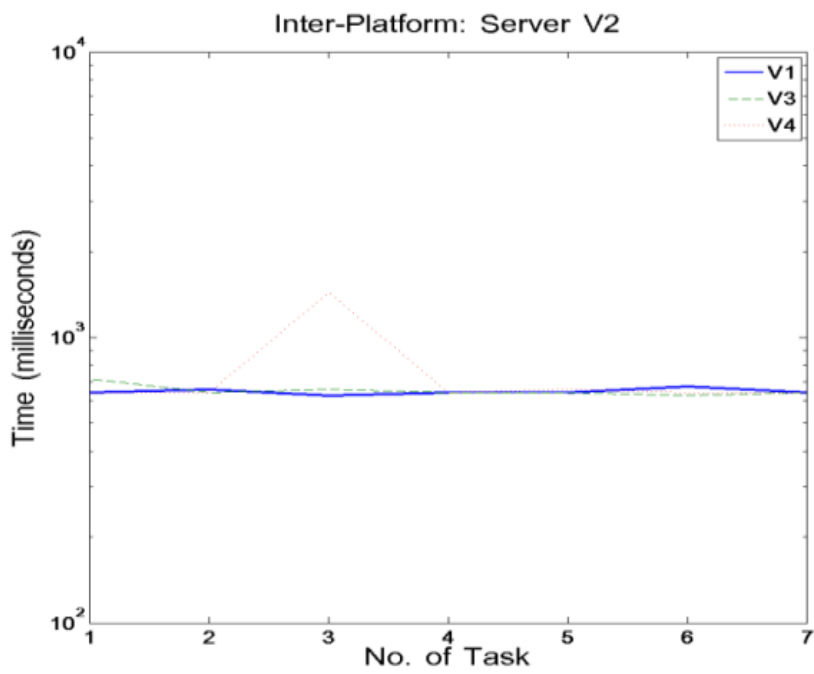

Figure 11. Inter-Platform signal respond in time (millisecond) for Server V2. Stable communication shown by most of the machine but the respond not so rapid compare to server $\mathrm{V} 3$ and $\mathrm{V} 4$. 


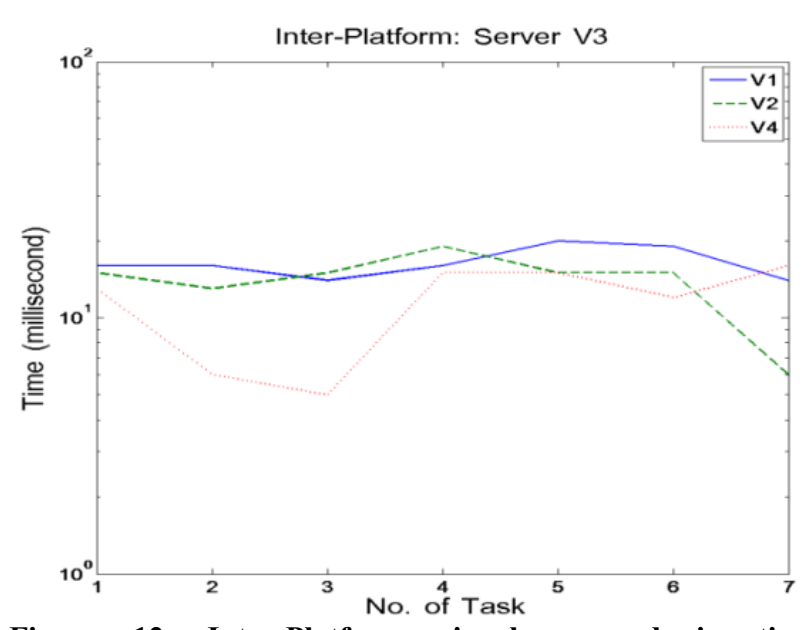

Figure 12. Inter-Platform signal respond in time (millisecond) for Server V3. The fastest respond is obtained by $V 3$ compared to $V 1$ and $V 2$ that used same operating system which is Window. If all manufacturing process could have this time respond it may give benefit to the manufacturing management in delay traceability and expedite the contingency plan in order to meet the market demand.

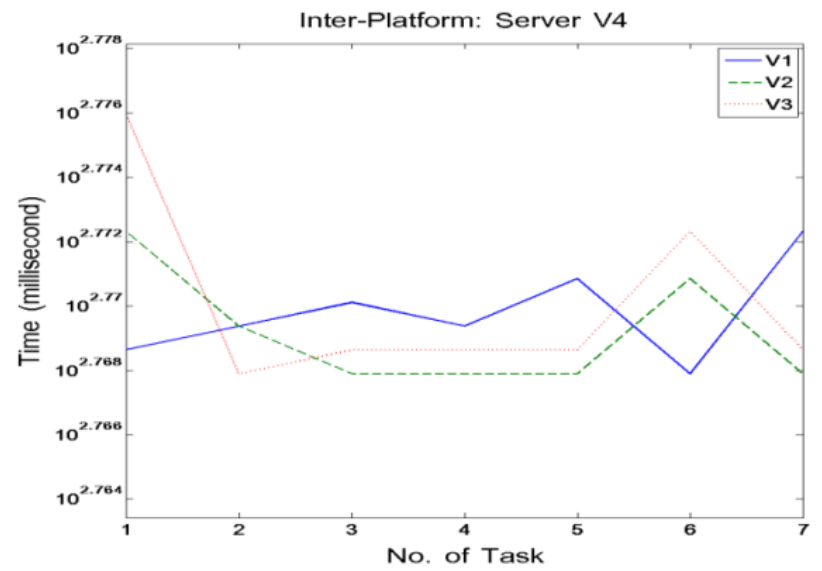

Figure 13. Inter-Platform signal respond in time (millisecond) for Server V4. Linux as an operating system for $\mathrm{V} 4$ also give better respond even the machine does not frequently used for programming development. Linux as an operating system offered the stability in system security compared to others operating system.

\section{Conclusion}

Stable communication showed by most of the machine but the respond not so rapid compare to server V3 and V4 however, instability of connections show in server V1 in one way communication. The fastest respond is obtained by V3 compared to V1 and V2 that used same operating system which is Window. Linux as an operating system for V4 also give better respond even the machine does not frequently used for programming development. Linux as an operating system offered the stability in system security compared to others operating system but because of the complexity of system to be used as well as operated become an occupied barrier.

Industry 4.0 required rapid respond for every issue to be measured by help from IoT. The fastest respond gained, the more efficient of manufacturing processes is achieve. However, in current practise of PLM and manufacturing management, it's difficult to obtain. The fastest time respond may give benefit to the manufacturing management in delay traceability and expedite the contingency plan to be implemented in order to meet the market demand. The IoT also give benefit to cost reduction in paperless management and sustainable development when market demand changed rapidly nowadays.

\section{Acknowledgments}

The researchers would like to thank the Malaysian Government, Universiti Teknikal Malaysia Melaka (UTeM) for their financial support and provision of facilities to carry out this study. Million thanks to Dr. Ahmad Yusairi Bani Hashim for the great thought and helpful comments. Also thank to The University of Tokushima Japan, for the supports. Their supports and comments are greatly acknowledged

\section{References}

1. Gu, Xiaoyuan. 2010. Toyota Recalls: Revealing The Value Of Secure Supply Chain. Diss. Massachusetts Institute of Technology.

2. Tech Drummer. 2008. Case Study: IBM \& Airbus: Tech Drummer

3. Jay Polonsky, M., \& Ottman, J. 1998. Stakeholders' contribution to the green new product development process. Journal of Marketing Management, 14(6), 533-557.

4. Baumann, H., Boons, F., \& Bragd, A. 2002. Mapping the green product development field: engineering, policy and business perspectives. Journal of Cleaner Production, 10(5), 409-425.

5. Lee, K. H., \& Kim, J. W. 2011. Integrating suppliers into green product innovation development: an empirical case study in the semiconductor industry. Business Strategy and the Environment, 20(8), 527538.

6. Stark, J. 2015. Product Lifecycle Management. (pp. 1-29). Springer International Publishing. (2015)

7. Bevilacqua, M., Ciarapica, F. E., \& Giacchetta, G. 2007. Development of a Sustainable Product Lifecycle In Manufacturing Firms: A Case Study. International Journal of Production Research, 45(1819), 4073-4098.

8. Gmelin, H., \& Seuring, S. 2014. Achieving sustainable new product development by integrating product life-cycle management capabilities. International Journal of Production Economics, 154, 166-177.

9. Johnson, M.E., Cochran, J.J., Cox, L.A., Keskinocak, P., Kharoufeh, J.P., Smith, J.C. 2010. Product/Service Design Collaboration: Managing the Product Life. Wiley Encyclopedia of Operations Research and Management Science. John Wiley \& Sons, Inc.

10. Wiesner, S., Freitag, M., Westphal, I., \& Thoben, K. D. 2015. Interactions between service and product lifecycle management. Procedia CIRP, 30, 36-41. 
11. Tao, F., Wang, Y., Zuo, Y., Yang, H., \& Zhang, M. 2016. Internet of Things in product life-cycle energy management. Journal of Industrial Information Integration, 1, 26-39.

12. Främling, K., Holmström, J., Loukkola, J., Nyman, J., \& Kaustell, A. 2013. Sustainable PLM through intelligent products. Engineering Applications of Artificial Intelligence, 26(2), 789-799.

13. Kiritsis, D. 2011. Closed-loop PLM for intelligent products in the era of the Internet of things. Computer-Aided Design, 43(5), 479-501.

14. Schuh, G., Rozenfeld, H., Assmus, D., \& Zancul, E. 2008. Process oriented framework to support PLM implementation. Computers in industry, 59(2), 210218.

15. Mourtzis, D. 2016. Challenges And Future Perspectives For The Life Cycle Of Manufacturing Networks In The Mass Customisation Era. Logistics Research, 9(1), 1-20.

16. Mourtzis, D., Doukas, M., \& Psarommatis, F. 2015. A Toolbox For The Design, Planning And Operation Of Manufacturing Networks In A Mass Customisation Environment. Journal of Manufacturing Systems, 36, 274-286.

17. Ståhl, J. E., Gabrielson, P., Stål, C., \& Andersson, C. 2012. ACMFDAOALIDBM. In 45th CIRP Conference on Manufacturing Systems 2012.

18. Xue, M., \& Zhu, C. 2009. The Socket Programming and Software Design For Communication Based On Client/Server. In Circuits, Communications and Systems, 2009. PACCS'09. Pacific-Asia Conference on 2009, (pp. 775-777). IEEE. 